\title{
Analisis Energi Aktivasi Pada Variasi Kecepatan Udara Dan Laju Reaksi Pembakaran Briket Limbah Kelapa Tua, Kelapa Muda Dan Kakao
}

\author{
Wahidin Nuriana ${ }^{1}$, Agus Suryanto ${ }^{2}$, Mustafa Kamal ${ }^{3}$ \\ ${ }^{1}$ Fakultas Teknik, Universitas Merdeka Madiun, Jl. Serayu No. 79, Madiun, 63133 \\ E-mail:nuriana@unmer-madiun.ac.id \\ ${ }^{2}$ Fakultas Pertanian, Universitas Merdeka Ponorogo, Jl. Pacar No.35, Ponorogo, 63418 \\ E-mail: agusunmer@yahoo.co.id \\ ${ }^{3}$ Fakultas Teknik, Universitas Merdeka Madiun, Jl. Serayu No. 79, Madiun, 63133 \\ E-mail:kamal@unmer-madiun.ac.id
}

\begin{abstract}
The purpose of this study was to obtain activation energy with the rate of combustion air, reduced mass weight and reaction rate of combustion of charcoal briquettes from biomass waste of old coconut, young coconut, cacao waste with carbonization at a temperature of $4000 \mathrm{C}$, for $30,60,90$ and 120 minutes. The study was conducted in a laboratory, with 3 (three) repetitions. The study was carried out by sorting raw materials, chopping, drying, carbonizing, grinding, sifting, adding tapioca glue to print, and pressing at $115 \mathrm{~kg} / \mathrm{cm} 2$. The results of the briquette were analyzed for heat, the highest calorific value of old coconut waste, young coconut, cocoa waste was analyzed for activation energy during the combustion process using DSC by varying the air heating rate of $20,30,40 \mathrm{ml} /$ minute. The highest yield of old coconut briquette heating value is $6,927 \mathrm{cal} / \mathrm{g}$ with 90 minutes carbonization time. The lowest activation energy is $\mathbf{1 3 3 . 2 0}$ joules / gram on old coconut briquettes with an air speed of 40 ml / minute. In the rate of combustion reaction by thermogravimetry with Thermal Gravimetry Analyzer (TGA), the greatest reduction in mass weight on old coconut waste briquettes compared to young coconut and cocoa waste briquettes was $55.34 \%$ from 590.5 oC to $599.2 \mathrm{oC}$.
\end{abstract}

Keywords —: Briquettes; old coconut; young coconut; cocoa; calorific value.

\section{PENDAHULUAN}

Energi merupakan kebutuhan yang urgen bagi kehidupan manusia, kebutuhan BBM makin hari makin meningkat. Sebagai contoh konsumsi energi disegala sektor makin meningkat, antara lain bidang transportasi, listrik, industri dan domestik. Potensi biomasa di Indonesia khususnya biomasa limbah pertanian (limbah kulit kelapa tua, kelapa muda dan kakao) tersedia dalam jumlah banyak dan murah, tetapi pemanfaatannya belum maksimal. Di samping sebagai bahan bakar, limbah-limbah tersebut dapat dimanfaatkan sebagai bahan baku arang aktif, kertas karbon, batu baterai dan lain-lain. Pada umumnya limbah pertanian hanya di pakai sebagai bahan bakar yang penggunaannya langsung dibakar, sehingga dapat menimbulkan pencemaran lingkungan (Jati, et al., 2005; Nuriana, 2013). Konversi limbah kulit kelapa muda, kelapa tua dan kakao menjadi briket .akan memperbesar densitas, sehingga meningkatkan nilai ekonomis dan lebih praktis dalam pengangkutan serta penyimpanan. Bahan bakar dalam bentuk briket selain mempunyai nilai kalor yang tinggi dapat menyala dalam waktu yang lama (Lusia, 2008).

Penelitian ini untuk memperoleh nilai kalor dengan proses karbonisasi dengan suhu $400^{\circ} \mathrm{C}$ dengan variasi waktu, kebutuhan energi aktivasi pada reaksi pembakaran dan aplikasinya, dibutuhkan data pengurangan bobot masa, laju reaksi pada produk briket limbah kulit kelapa tua, kelapa muda dan kakao.

\section{METODE PENELITIAN}

Penelitian dilaksanakan dan dianalisis secara laboratorium, perlakuan dilakukan pengulangan 3 (tiga) kali. Perancangan percobaan menggunakan rancangan acak lengkap dengan variabel pengaruh waktu karbonisasi dan variabel respon adalah densitas, nilai kalor. Bobot pengurangan masa dan laju ketika proses reaksi pembakaran.

\section{A. Bahan dan Alat}

Bahan yang digunakan pada penelitian ini adalah: limbah kelapa tua (kulit, sabut, tempurung), kelapa muda (kulit, sabut, tempurung), kakao, tepung kanji, air, aluminium foil sebagai pembungkus saat dioven. Peralatan yang dipakai dalam penelitian ini adalah oven, pisau, nampan, mortil, desikator, alat pencetak, alat press briket, gelas ukur, piknometer, erlenmeyer, labu volume, timbangan elektrik, ayakan 80 mesh, manometer, bomb calorimetry, unit Thermo Gravimetry Analayzer (TGA), Differential Themo Analayzer (DTA).

\section{B. Pembuatan Briket}


Website : http://agritek.unmermadiun.ac.id/index.php/agritek

Limbah kelapa tua, kelapa muda dan kakao disortasi, dikeringkan di bawah sinar matahari 3 hari untuk menurunkan kadar air. Dilanjutkan karbonisasi pada suhu $400^{\circ} \mathrm{C}$ selama 30, 60. 90, 120 menit memakai oven. Kemudian ditumbuk, diayak dengan ayakan 80 mesh, dilanjutkan proses pencampuran dengan perekat/ lem kanji diaduk hingga homogen, dicetak dan dipress dengan tekanan $115 \mathrm{~kg} / \mathrm{cm}^{2}$ (Mahyoeno, dkk., 2005; Sulistyanto, dkk., 2005). Briket yang telah dicetak kemudian dikeringkan untuk mengurangi kadar air yang terkandung masuk bersama lem, dijemur di bawah terik sinar matahari selama \pm 3 hari. Briket dianalisis kadar air, densitas, nilai kalor, laju reaksi pembakaran, pengurangan bobot masa pada proses pembakaran. Dari karbonisasi dengan variasi waktu 30, 60, 90, 120 menit dipilih nilai kalor yang tertinggi dari masing-masing briket kemudian dianalisis laju reaksi dan pengurangan bobot masa pada proses reaksi pembakaran.

\section{III.HASIL DAN PEMBAHASAN}

\section{A. Uji Nilai kalor Briket Limbah Kelapa Tua, Kelapa Muda Dan Kakao}

Setelah dilakukan proses karbonisasi pada suhu $400^{\circ} \mathrm{C}$ dengan variasi waktu 30, 60, 90, 120 menit dan dibuat briket selanjutnya ditumbuk dan diayak hingga ukuran 100 mesh, untuk memudahkan uji nilai kalor dalam pembakaran dengan oksigen dalam bomb calorimetry (Syamsiro, 2007). Makin kecil ukuran partikel akan memperbesar permukaan bakar sehingga bahan makin cepat terbakar (Subroto, 2006; Nuriana, 2013). Nilai kalor merupakan parameter utama dalam penilaian suatu bahan bakar atau energy (Scroder E., 2006; Tirono, 2011; Nuriana, 2013).

Tabel 1. Nilai kalor briket limbah kelapa tua, kelapa muda dan kakao pada karbonisasi suhu $400^{\circ} \mathrm{C}$ dengan variasi waktu karbonisasi $30,60,90,120$ menit

\begin{tabular}{|c|c|c|c|}
\hline No. & Waste & $\begin{array}{c}\text { Time } \\
\text { (minutes) }\end{array}$ & $\begin{array}{c}\text { Heating value } \\
\text { (cal/g) }\end{array}$ \\
\hline 1. & Old coconut & 30 & 6.635 \\
\hline & & 60 & 6.882 \\
\hline & & 90 & 6.927 \\
\hline & & 120 & 6.879 \\
\hline 2. & Young coconut & 30 & 5.457 \\
\hline & & 60 & 5.846 \\
\hline & & 90 & 5.328 \\
\hline & & 120 & 5.740 \\
\hline 3. & Cocoa & 30 & 4.925 \\
\hline & & 60 & 5.059 \\
\hline & & 90 & 4.967 \\
\hline & & 120 & 4.787 \\
\hline
\end{tabular}

Sumber: Nuriana, 2017

Gambar 1. Pengaruh waktu (30, 60, 90,120 menit) karbonisasi terhadap nilai kalor arang limbah kelapa tua, kelapa muda dan kakao

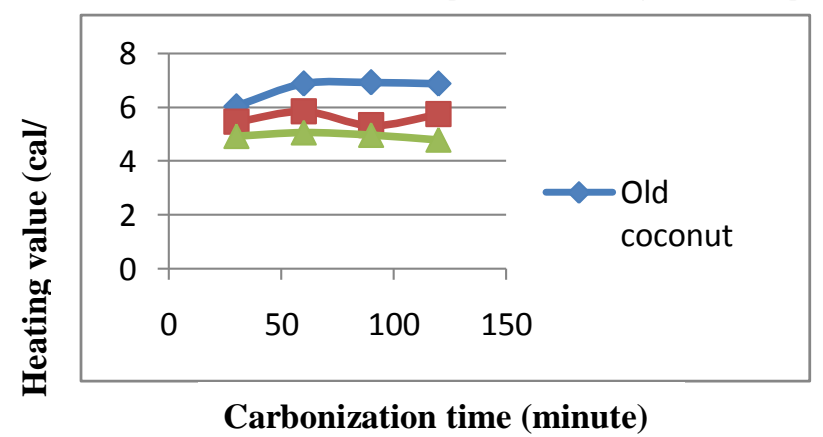

Dari ketiga bahan briket limbah kelapa tua, kelapa muda, kakao masing-masing nilai kalor 6.927 cal/g dengan lama karbonisasi 90 menit, $5.846 \mathrm{cal} / \mathrm{g}$ dengan lama karbonisasi 60 menit, $5.059 \mathrm{cal} / \mathrm{g}$ lama 60 menit merupakan nilaikalor tertinggi dan dipilih untuk diuji energi aktivasi dan laju reaksi pembakarannya. Hasil briket diuji energi aktivasinya dengan Differential Scan Calorimetry (DSC). Kemudian diuji dengan TG, DTG untuk pengurangan bobot dan laju reaksi pembakaran. Dari hasi briket limbah kelapa tua, kelapa muda, kakao dengan nilai kalor briket tertinggi ditunjukkan pada gambar grafik di bawah ini.

Gambar 1. Nilai kalor briket limbah kelapa tua $6.927 \mathrm{cal} / \mathrm{g}$ dengan lama karbonisasi 90 menit, kelapa muda nilai kalor, 5.846 cal/g dengan lama karbonisasi 60 menit, kakao $5.059 \mathrm{cal} / \mathrm{g}$ dengan lama 60 menit 


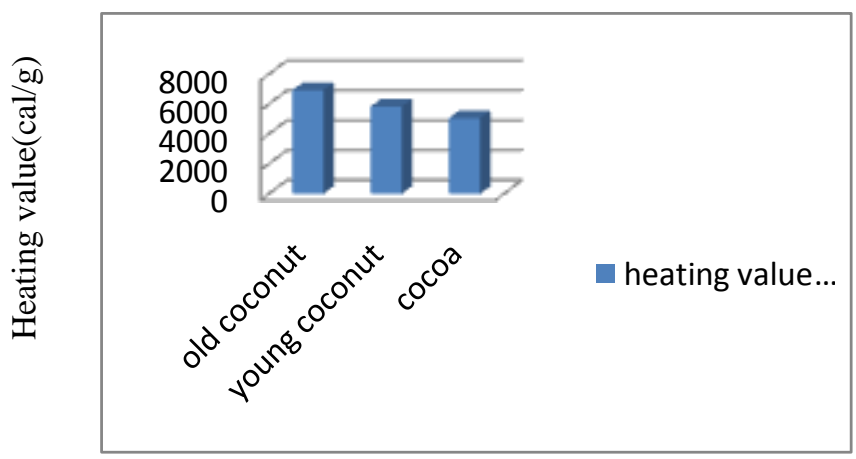

\section{B. Uji Energi Aktivasi}

Hasil energi aktivasi dengan pengujian memakai alat DSC (Differensial Scaning Calorimetry) pada briket kelapa tua, kelapa muda dan kakao masing-masing bobot berbeda dilakukan dengan variasi laju aliran udara 20,30,40 ml/menit dinyatakan pada tabel 2 di bawah.

Tabel 2. Hasil energi aktivasi pada briket kelapa tua, kelapa muda dan kakao dengan variasi laju aliran udara $20,30,40 \mathrm{ml} / \mathrm{menit}$

\begin{tabular}{|c|c|c|c|}
\hline \multirow{2}{*}{ Laju udara (ml/menit) } & \multicolumn{3}{|c|}{ Energi aktivasi briket ( ( J/g) } \\
\cline { 2 - 4 } & Kelapa tua & Kelapa muda & Kakao \\
\hline 20 & 163,80 & 195,40 & 216,60 \\
\hline 30 & 150,50 & 182,4 & 207,10 \\
\hline 40 & 133,20 & 138,4 & 185,60 \\
\hline
\end{tabular}

Hasil perbandingan energi aktivasi briket kelapa tua, kelapa muda dan kakao dengan variasi laju aliran udara 20,30,40 $\mathrm{ml} /$ menit dan bobot sampel masing-masing pada uji DSC berbeda, dapat dilihat pada gambar 3 grafik di bawah

Gambar 3. Grafik Energi aktivasi briket kelapa tua, kelapa muda dan kakao pada variasi laju aliran udara 20,30,40 ml/menit

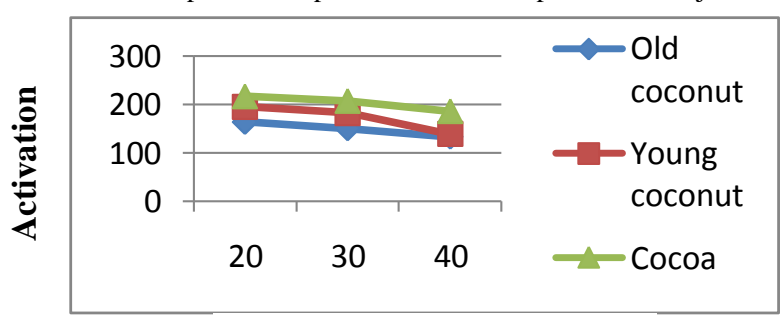

Heating rate $\mathrm{ml} / \mathrm{secan}$

Makin tinggi laju aliran udara, maka energi aktivasi pada briket kelapa tua, kelapa muda dan kakao menurun secara signifikan. Hal ini disebabkan karena makin tinggi laju aliran udara, maka energi aktivasi yang diperlukan untuk reaksi pembakaran makin kecil. Energi aktivasi tergantung pada nilai kalor briket, energi aktivasi akan rendah bila bahan bakar tersebut mempunyai nilai bakar yang tinggi, ini terjadi pada briket limbah kelapa tua. Kecepatan aliran udara lebih tinggi memiliki kandungan oksigen lebih banyak yang dapat membantu terjadinya perubahan secara lebih sempurna. Karena telah terbakar lebih sempurna, maka akan memerlukan energi aktivasi yang rendah (Aries, dkk.,2013).

Energi aktivasi tertinggi pada briket kelapa tua, kelapa muda dan kakao dengan variasi laju udara ditunjukkan kurva-kurva. Pada gambar di bawah kurva energi aktivasi, terlihat suhu tertinggi energi aktivasi pada puncak kurva dari briket limbah kelapa tua pada variasi laju udara $20,30,40 \mathrm{ml} / \mathrm{menit}$.

Gambar 4. Kurva energi aktivasi pada laju udara 20ml/ menit dengan Differensial Scan

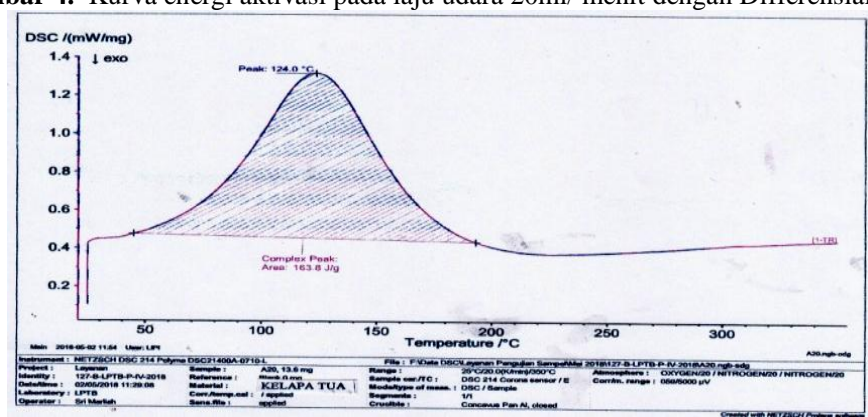

Calorimetry, energi aktivasi tertinggi pada puncak kurva suhu $124,0^{\circ} \mathrm{C}$.

Gambar 5. Kurva energi aktivasi briket limbah kelapa tua, pada laju udara 30ml/ menit dengan Differensial Scan Calorimetry, energi aktivasi tertinggi pada puncak kurva suhu $119,7^{\circ} \mathrm{C}$ 
Website : http://agritek.unmermadiun.ac.id/index.php/agritek

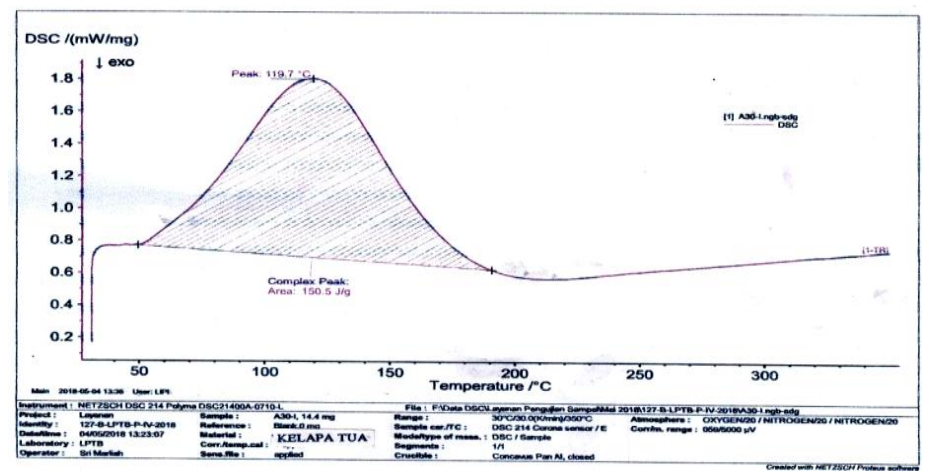

Gambar 6. Kurva energi aktivasi briket limbah kelapa tua pada laju udara 40ml/ menit dengan Differensial Scan Calorimetry, energi aktivasi tertinggi pada puncak kurva suhu $118,3^{\circ} \mathrm{C}$.

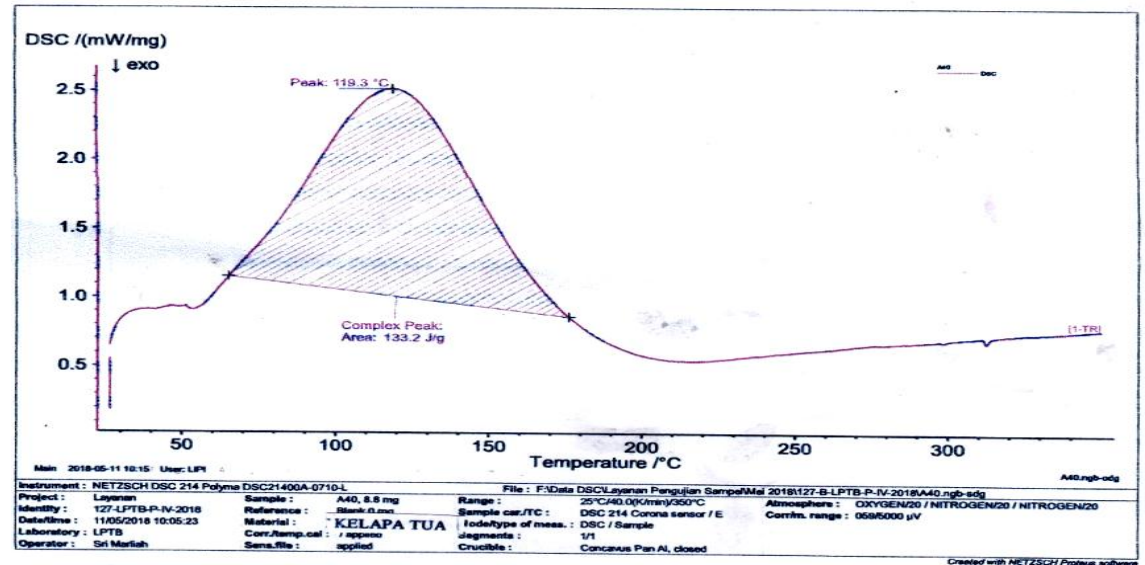

Pada ketiga kurva di atas terlihat makin tinggi puncak kurva dengan laju udara rendah, ini disebabkan oleh energi aktivasi reaksi pembakaran tinggi.

\section{Hasil pengurangan bobot briket dan laju reaksi pembakaran briket}

Dengan TG dan DTG Briket limbah kelapa tua mempunyai perubahan bobot masa dan laju reaksi sebagai berikut:

a. Perubahan bobot briket saat mulai pembakaran $40^{\circ} \mathrm{C}$ hingga $100^{\circ} \mathrm{C}$ berkurangnya bobot adalah 1,1 dan pada suhu $590,5^{\circ} \mathrm{C}$ hingga $599,2{ }^{\circ} \mathrm{C} 55,34 \%$. Pada DTG ditunjukkan sebagai proses endoterm, dan pada akhir pembakaran terjadi pengurangan masa arang secara lebih cepat.

b. Laju reaksi pembakaran adalah pada gambar 4.1 adalah $0,10 \% /$ menit. dengan laju udara $5 \mathrm{ml} / \mathrm{menit}$. Briket limbah kelapa muda mempunyai perubahan bobot masa dan laju reaksi sebagai berikut:

a. Perubahan bobot briket saat mulai pembakaran suhu $40^{\circ} \mathrm{C}$ hingga $79,5^{\circ} \mathrm{C}$ pengurangan bobot masa $6,04 \%$, dan pengurangan bobot $42,10 \%$. pada suhu $590{ }^{\circ} \mathrm{C}$ hingga $599,2^{\circ} \mathrm{C}$ pengurangan bobot secara drastis $50,09 \%$.

b. Laju reaksi pembakaran pada briket limbah kelapa muda adalah $0,22 \% /$ menit.

Briket limbah kakao mempunyai perubahan bobot masa dan laju reaksi sebagai berikut:

a. Perubahan bobot briket saat mulai pembakaran suhu $40{ }^{\circ} \mathrm{C}$ hingga $50,5^{\circ} \mathrm{C}$ pengurangan bobot masa $0,84 \%$, pada suhu 590 ${ }^{\circ} \mathrm{C}$ hingga $599,2^{\circ} \mathrm{C}$ terjadi pengurangan bobot $35,53 \%$.

b. Laju reaksi pembakaran pada briket limbah kelapa muda adalah $0,24 \%$ / menit.

Hasil penelitian ini, nilai kalor briket kelapa tua mempunyai laju reaksi pembakaran paling lambat atau rendah dibanding dengan laju pembakaran briket kelapa muda dan kakao. Pengaruh nilai densitas makin tinggi, maka nilai kalor briket makin tinggi pula dan laju pembakaran makin lambat atau rendah sesuai dengan penelitian Afif, dkk., 2014; Kurniawan, dkk., 2012).

Pengurangan bobot masa yang terbanyak pada briket limbah kelapa tua dibanding briket limbah kelapa muda dan kakao, adalah $55,34 \%$ dari suhu $590,5^{\circ} \mathrm{C}$ hingga $599,2{ }^{\circ} \mathrm{C}$ pada analisis dengan cara Thermogravimetry (Himawanto, D.A., dkk., 2011; Aries D. Himawanto, 2013).

\section{IV.KESIMPULAN}

1. Energi aktivasi rendah pada briket limbah kelapa tua dengan laju udara $40 \mathrm{ml} /$ menit; 
Website : http://agritek.unmermadiun.ac.id/index.php/agritek

2. Laju reaksi pembakaran briket limbah kelapa tua lebih rendah $(0,10 \% /$ menit $)$ dibanding dengan briket limbah kelapa muda dan kakao;

3. Nilai kalor tertinggi didapat pada briket limbah kelapa tua adalah $6.927 \mathrm{cal} / \mathrm{g}$ pada karbonisasi suhu $400^{\circ} \mathrm{C}$ dengan lama 90 menit dibanding limbah ke;apa muda dan kakao;

4. Harga densitas briket tinggi, maka nilai kalor mempunyai harga tinggi pula.

\section{UCAPAN TERIMA KASIH}

Kami mengucapkan terima kasih kepada yang terhormat:

1. Direktorat Jenderal Penguatan Riset dan Pengembangan, Kementerian Riset, Teknologo dan Pendidikan Tinggi dengan surat No. SP DIPA A-04206.1.401516/2017 dan Surat Perjanjian Nomor : 035/SP2H/LT/K7/KM/2018 Antara Koordinator Kopertis Wilayah VII dengan Rektor Universitas Merdeka Madiun tanggal 26 Februari 2018

2. Ketua Laboratorium Uji Polimer, P2F-LIPI Bandung.

3. Ketua jurusan Teknik Fisika, Teknik Fisika ITS Surabaya

4. Kepala Sekolah dan Kepala Laboratorium Kimia Analitik SMKN-3 Madiun

\section{VI.DAFTAR PUSTAKA}

Afif M.Almu, Syahrul, Yesung. A.P.,2014. Analisa Nilai Kalor Dan Laju Pembakaran PadaBriket Campuran Biji Nyamplung (Calophyllm Inophyllum) Dan Abu Sekam Padi, Jurnal Dinamika Teknik Mesin, Volume 4 No. 2m Juli 2014.

Aries D. Himawanto, 2013. Penentuan Energi Aktivasi Pembakaran Bruket Char Sampah Kota Dengan Menggunakan MetodeThermogravimetry Dan Isothermal Furnace. JurnalRotasi, Volume 15, No, 3, Juli 2013.

Himawanto, D.A., Indarto, Saptoadi, H, Rohmat T. A., 2011. Karakteristik Dan Pendekatan Kinetika Global Pada Pirolisis Lambat Sampah Kota Terseleks Reaktor, ISSN 08520798, Vol. 13 Juni 2011, Hal. 141-146

Himawanto, D.A., Sidhi P.R.,Indarto, Saptoadi, H, Rohmat T. A., 2011. Analisa Thermogravimatry Pembakaran Briket Char Bambu, Jurnal Teknik, Vol. 11 no. 1,hal. 77-84

Himawanto, D.A., Indarto, Saptoadi, H, Rohmat T. A., 2012. Thermogravimetric Analysis and Global Kinetics of Segregated MSW Pyrolysis, Modern Applied Science, 6 (1), Hal. 120-119

Jati E, 2005. Determination Of Charcoal Calorie Fuel From A Number Of Wood Species And Length Of Pyrolysis. J PhysicsIndonesia Majoring in Physics FMIPA UGM. Yogyakarta 2005; p. 11-13

Kurniawan Eddy, Budi Wahyudi S., Muslichin H., 2012 Karakteristisasi Dan Laju Pembakaran Biobriket Campuran Sampah Organik Dan Bungkil Jarak (Jatropha curcas L.). Jurnal Rekayasa Proses, Vol. 6, No. 2, 2012

Kurniawan Eddy, 2012. Model Matematis Laju Pembakaran Biobriket Campuran Sampah Organik Dan Bungkil Jarak (Jatropha curcas L.).

Mahajoeno Edwi, 2005, Energi Alternatif Pengganti BBM Potensi Limbah Biomassa Smart Sebagai Sumber Energi Terbarukan.

Nuriana W., 2013. Synthesis Preliminary Studies Durian Peel Bio Briquettes As an Alternative Fuels, Energy Procedia Journal 47 (2014), 295-302

Nuriana W., 2018. Karakteristik Biobriket Limbah Kelapa (Tua, Muda) Dan Kakao Sebagai Energi Terbarukan Pada Variasi Waktu Karbonisasi. Kementrian Hukum Dan Hak Asasi Manusia, Surat Pencatatan Ciptaan, Nomor EC00201800774, Tanggal Permohonan: 19 Januari 2018

Scroder Eliabeth, Experiment on the Generation of Activated Carbon from Biomass, Institute for Niclear and Energy Technologies Forschungs Karlsruhe, Hal. 106-111, Germany 2006.

Tirono M.; Sabit, Efek Suhu Pada Proses Pengarangan Terhadap Tempurung Kelapa Jurnal Neutrini, Vo 3,No. 2. Fakultas Sains dan Teknologi UIN Maulana Malik Ibrahim Malang, 2011.

Syamsiro M.; Harwin Saptoadi, 2007. Pembakaran Briket Biomassa Cangkang Kakao:Pengaruh Temperatur Udara Preheat. Seminar Nasional Teknologi Teknik Mesin UGM Yoyakarta.

Sulistyanto Amin, 2005. Pengaruh Variasi Bahan Perekat Terhadap Laju Pembakaran Biobriket Campuran Batubara Dan Sabut Kelapa

Subroto, 2006. Karakteritik Pembakaran Biobriket Campuran Batubara, Ampas Tebu, Jerami.Media Mesin, Vol. 2, Juli 2006, 47-54. 